\title{
Effect of Unilateral Mandibular Implant-Tooth Supported Telescopic Prosthesis on the Supporting Structures (In Vitro Study)
}

\author{
Isaeida Abdulla Ali Mohamed ${ }^{1}$, Seham Ahmed Hanafy², Magdi Abd El-Meguid Awadallah ${ }^{3}$ \\ ${ }^{1}$ BDS, Faculty of Dentistry, Benghazi University, MS, Alexandria University, Egypt \\ ${ }^{2}$ Professor of Dental Materials Faculty of Dentistry University of Alexandria, Egypt
}

${ }^{3}$ Professor of Prosthodontics, Alexandria University Faculty of Dentistry, Alexandria, Egypt

\begin{abstract}
Introduction: Distal-extension removable partial dentures (RPDs) are associated with several problems related to their stability, retention, esthetics, and masticatory efficiency.Loading of a Kennedy class II denture is complicated by the mismatch of tissue resiliency and the abutment teeth, which have different viscoelastic responses. The rotational movements of RPDs might produce terminal torque forces against the abutment teeth and the soft tissue. The incorporation of dental implants for the partial support of removable prostheses offers a practical adjunct in the fulfilment of the functional stability, preservation of remaining alveolar bone and minimizing of the resultant rotational forces. Accordingly, in case of a long span unilateral distal extension case, the use of an implant could change the mandibular removable partial denture from tooth/tissue-supported to a tooth/implant-supported situation. Telescopic crown retained removable partial denture is one of the options which provides satisfactory support and preservation of the supporting structures Applying the concept of simplifying the design dictates a unilateral partial denture for class II cases. This design could be more easily accepted by patients. The aim of the study: The aim of this study is to laboratory measures the strain at supporting structures of unilateral mandibular implant -tooth supported telescopic retained removable partial over denture lined with thermoelastic acrylic base in class 11 Kennedy classification. Materials and methods:10 acrylic mandibular model Kennedy class II were constructed incorporatingone implantplaced in the first molar region .upon this model,two experimental telescopic overdentures were fabricated as follows: Group A unilateral implant -tooth supportedtelescopic retained removable partialover denture with hard acrylic base GroupBunilateral implant -tooth supported telescopic retained removable partialover denture with thermo elastic acrylic base, Four linear strain gauges were bonded to the acrylic resin modelat the buccal and lingualsurface of each abutment tooth andimplant. Strains were measured on each model. Micro Strain measurements were performed under vertical and oblique loading using a universal testing machine. Result: Significant differences between groups and between sites of strain gauges were detected. Strains recorded for all groups were compressive (negative) in nature. Group A demonstrated the highest strain, group B recorded the lowest strain. For group A, the highest strain was recodedat the buccal side. Conclusion: Reduction of stress to the distal-extension base was observed with the resilient layer (groups $B$ ), compared with the(control, group A) The results of the present study elucidate that the Thermo-elastic acrylic resin TOD exhibited low strainthan hard acrylic resin TOD
\end{abstract}

Keywords: implant overdenture, telescopic over denture, unilateral partial denture, thermo elastic, strain gauge

\section{Introduction}

Posterior free end edentulous areas are more prevalent among population. The problem of support, retention and stability is usually associated with distal extension removable partial dentures (RPDs)[1,2]that affects the prognosis of prosthesis.

The distal extension removable partial denture derives it's support from two different kinds of tissue, namely the tooth which is representing a relatively immovable support, and the mucosa overlying the edentulous residual alveolar ridges, those two tissues have different degree of displaceability. When the functional occlusal load is applied to the denture base, an axis of rotation is created around the most distal abutment teeth causing a torquing effect on the clasped teeth which are liable to cause premature breakdown of it is supporting bony tissues. At the same time edentulous ridge resorption is likely to occur. This problem is more significant in the mandibular arch where less tissue support is available [3].

Rehabilitation of a partially edentulous patient can be established using a wide range of prosthetic treatment options including simple conventional removable partial denture, over denture, fixed partial denture or dentalimplants [4].

The incorporation of dental implants for the partial support of removable prostheses offers a practical adjunct in the fulfilment of the functional stability, preservation of remaining alveolar bone and minimizing of the resultant rotational forces [5].

Keltjens et al (1993)[6] stated that the fitting of implants under distal extension of the base of the RPDs results in better occlusal stability.

Accordingly, in case of a long span unilateral distal extension case, the use of an implant could change the mandibular removable partial denture from tooth/tissuesupported to a tooth/implant-supported situation. Thus it might not only improve denture retention, support and stability but also might help in preserving of that what remains $[7,8]$.

RPD retained by telescopic crowns (TRPD) on the residual dentition is an alternative treatment option to a conventional clasp retained RPD $[9,10]$. 


\section{International Journal of Science and Research (IJSR) \\ ISSN (Online): 2319-7064}

Index Copernicus Value (2013): 6.14 | Impact Factor (2015): 6.391

Combining remaining teeth with implants inserted in strategic positions, by fabrication of double-crown retained dentures (DCRDs), could enable polygonal abutment arrangementsand, therefore, stabilize thesuperstructure [11].

Telescopic crowns have been used successfully for several decades to connect dentures to natural teeth and/or implants. The telescopic crown concept ensures maximally favourable masticatory force transmission, which always takes place axial to the abutments. Regarding the use of telescopic crowns with implant-supported over dentures, only limited data are available; however, the results so far indicate that this treatment modality can lead to predictable long-term treatment outcomes [12].

Recently, the CAD/CAM system has gained attention as the metal processing technique substitutefor the conventional lost wax technique in dentistry. With time, the processing accuracy of the CAD/CAMsystem has remarkably improved owing to improvementand development of the measuring apparatusand processing machine. One ultimate benefit isthat the fitting precision of crowns fabricated usingthe CAD/CAM system is drawing closer to that ofthe cast crown [13].

Thermo-elastic acrylic resin material called "Versacryl" was introduced in the last decade, "Versacryl" is a multi-purpose heat-sensitive cross-linkedacrylic resin that remains thermoelastic after polymerization and chemically bond to the acrylic denture base. As claimed by the manufacturer; it can create any part of a denture to become adjustable, using only warm water. It can be used to replace clasps, utilize undercuts, and produce repeatable thermo-relines .It is also used as stress breaker, shock absorber for implants, flexible denture flanges, and tissue conditioning material. The thermo-elastic property of Versacryl after polymerization, allows better adaptation to the soft tissues [14].

Versacryl is available in Heat Cure or Self Cure and no special equipment is needed to process with a little experience, some very sophisticated assemblies can be constructed in a minimum of time [14].

A strain gauge is a device used to measure the strain of the object. The most common type of strain gauge consists of an insulating flexible backing that supports a metallic foil pattern. The gauge is attached to the object by a suitable adhesive. As the object is deformed, the foil is deformed, causing its electrical resistance to change $[1,15]$.

It is interesting to study the hypothesis whether the use of unilateral implant -tooth supported telescopic retained removable partialover denture with thermoelastic acrylic base could be advantageous to the patient when assisted by one implant considering its processing advantage in stress reduction on supporting structures.

\section{Material and Method}

In this in vitro study, linear strain gauge wasused to compare the microstrain induced by differentprosthetic options using single posterior implant forrestoring lower unilateral mandibular distal extension saddle (Kennedy class II).

\subsection{Fabrication of the mandibular acrylic resin model}

Commercially available rubber mandibular models with acrylic teeth were used*. This model contained anatomically shaped teeth with roots which can be inserted and removed from the model. the mandibular canine as the last standing abutment ,for constructingthis model ,impressionof a readymade standard acrylic castafter modification, will be made using silicon rubber base impression materialthis will be followedby processingcastintoheat acrylic resin. The tooth No 3are removed to expose their sockets. $2 \mathrm{~mm}$ resilient thermoplastic material layer was adapted by vacuum press Machine to cover the residual ridge and lining the sockets of the abutment teeth resembling the oral mucosa \& periodontal ligament, the thermoplastic layer is adapted well to the acrylic base using cyano acrylate adhesive.

\subsection{Fabrication of drilling guide template andimplant installation}

The drilling guide template is an acrylic replica of the trial denture that replaces the missing teeth to control the position of the implant related to the position of the $1^{\text {st }}$ molar.One Implant fixture ( $4.5 \mathrm{~mm}$ in diameter, $12.5 \mathrm{~mm}$ long) ${ }^{*}$ was used at the site of the $1^{\text {st }}$ molar in edentulous side of the model.

\subsection{Partial denture construction}

A telescopic partial over denture (metallic framework and acrylic resin recordblock) (without any denture teeth).Was constructed over the model. Ten experimental partial over dentures were then constructed (5 dentures for each group). On the prepared acrylic resin model, different prosthetic designs were constructed as follows:

Group A: (unilateral implant -tooth supportedtelescopic retained removable partialover denture with hard acrylic base)(UTOD)

Group B: (unilateral implant -tooth supported telescopic retained removable partialover denture (UTOD) lined with thermo elastic material).

For each groups the following steps will be performed:

The mandibular cast will be fixed to the base of the milling machine that will be used to prepare the implant abutment and the last standing abutment (Canine) with abuccal shoulder and a lingual deep chamfer finishing line to receive the telescopic crown prosthesis.

The straight abutment was screwed to their corresponding implant and preparedto attain adome shapedabutment of 3$4 \mathrm{~mm}$ approximately in height.the telescopic crowns fabricated using a CAD/CAM system This results in higher predictability for the definitive restorations.

\section{Construction of metal framework}

The prepared plastic pattern of the coping was casted in the metal and seated on the acrylic cast on the abutments. The telescopic crowns plastic patterns were seated in right position on the copings.

Volume 5 Issue 6, June 2016 www.ijsr.net 


\section{International Journal of Science and Research (IJSR) \\ ISSN (Online): 2319-7064}

Index Copernicus Value (2013): 6.14 | Impact Factor (2015): 6.391

Wax pattern of the partial denture framework was constructed connecting both telescopiccrowns plastic pattern they casted in metal in a conventional casting procedures.

\subsection{Fabrication of acrylic biting block}

All prepared denture bases will be covered by Narrow acrylic resin occlusal block resembling the artificial Teeth On the crest of the ridge (unilateral) in each group.

Acrylic block (6 $\mathrm{cm}$ lengths and $5 \mathrm{~mm}$ thickness), will be fabricated so attached to the acrylic denture base. The wax rim is flasked and converted to acrylic bite block. After deflasking, the acrylic bite block is finished and Notches are prepared centralized on the surface of the blocks throw which the occlusal load will be applied

\subsection{Installation of strain gauges}

A self-protected linear gauge [KoyomaSrain Gages, Japan] were used for this study as follow:

1. Small channels about $4 \mathrm{~mm}$ length are prepared in the acrylic model at the buccal and lingual surfaces of the implant and the abutment canine tooth to receive the strain gauge rosettes.

2. Four strain gauges are installed on the selected sites on the acrylic model and cemented using A strain gauge adhesive [* CC-33A,EP-34B Strain Gagecement] then covered by self-cured acrylic resin. to measure the microstrains in themediumsurrounding the abutment tooth and implant, respectively.(Fig. 1).

3. The strain gauge sensors will be connected to a strain meter to measure the micro-strains that result from the applied load.

4. The strain gauges were covered by self-cured acrylic resin.

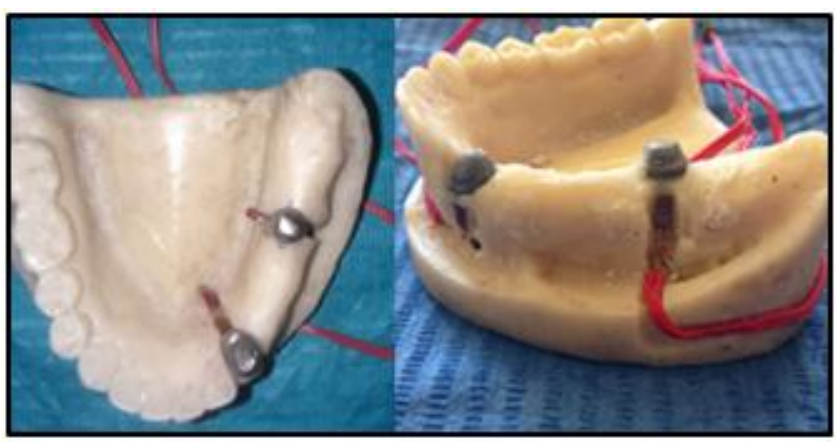

Figure 1: Acrylic resin model with strain gauge sensors.

\subsection{Load application using the universal testing machine}

The casts was inserted into the universal test machine and well seated between its two plates. The universal testingmachine was used to applya load ofabout 300 $\mathrm{N}^{*}[16,17](66$ pounds ) was applied at a constant rate (crosshead speed) of $10 \mathrm{~mm} / \mathrm{min}$. This amount of force is regarded as maximal occlusal force for overdentures at the first molar area. The point of load application was selected at the site of the central occlusal fossa of the first molar and notched in the acrylic resin surface of the record block with a diamond bur.

This was done for reproducibility, standardization, accommodation of the tip of the loading pin in the same location (notch), and to prevent slippage of the pin, across denture bases inan axial downward direction. during the strain measurements test.

All measurements were repeated 5 times allowing at least 5 minutes for recovery, For both groupsthe same steps were repeated. The load was applied in two directions:

- Vertical load application.

- Obliqueload application

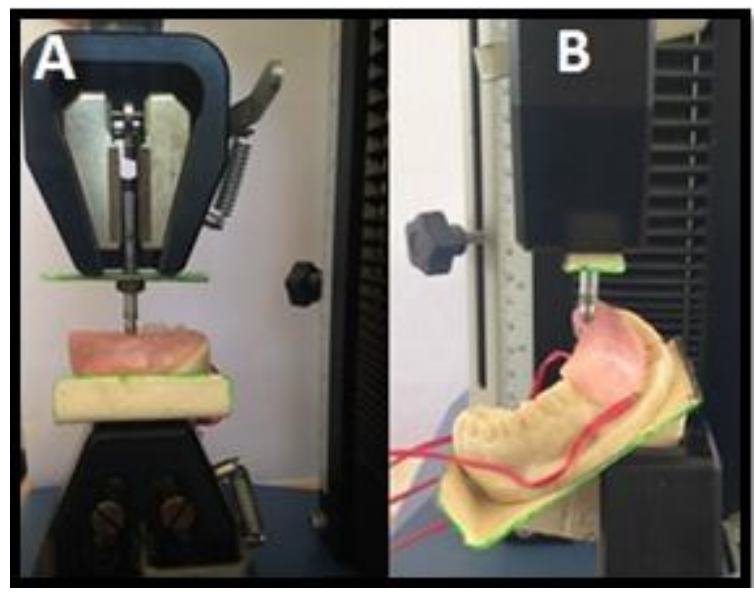

Figure 2: (A) vertical loading, (B) oblique loading.

\section{Statistical Analysis}

The resulting data were fed to the computer and analyzed using IBM SPSS software package version 20.0.Quantitative data were described in Newton as range (minimum and maximum) mean, standard deviation and median. The distributions of quantitative variables were tested for normality using Kolmogorov-Smirnov test, Shapiro-Wilk test and D'Agstino test and revealed a normally distributed data. Accordingly, Comparison between two independent data was done using independent t-test; Comparison between multiple data was done using ANOVA with repeated measures and Post Hoc test was assessed using Tukey LSD. Significance test results were quoted as two-tailed probabilities. Significance of the obtained results was judged at the $5 \%$ level. A p-value of less than 0.05 was considered statistically significant.

\section{Results}

Analysis of micro-strain measurements around thetooth abutment and implant abutment under the two different designs are shown in Tables 1-4 and Graphs 1 -4.Under vertical and oblique load.

The minimum micro-strain measurements were recorded in gp II. The difference was statistically significant between gp I \& II as $\mathrm{P}$ value $<0.001 *$.

The maximum micro-strain measurements recorded at the buccal side of the tooth and implant were found in two groups undervertical loading the difference of microstrain measurements between the two groups is significantas $\mathrm{P}$ value $<0.001 *$. 


\section{International Journal of Science and Research (IJSR) \\ ISSN (Online): 2319-7064}

Index Copernicus Value (2013): 6.14 | Impact Factor (2015): 6.391

The maximum micro-strain measurements recorded at the buccal side of the abutment and implant were found in group I.

The maximum micro-strain measurements recorded at the buccal side of the abutment and implant are found in two groups under oblique loadthe difference of microstrain measurements between the two groups is significantas Pvalue $<0.001 *$.

Table 1: Comparison between the recorded mean micro strain values at the examined surfaces of the abutment toothfor group Aand B under vertical load

\begin{tabular}{|c|c|c|c|c|}
\hline & $\begin{array}{c}\text { Group I } \\
(n=25)\end{array}$ & $\begin{array}{c}\text { GroupII } \\
(n=25)\end{array}$ & $\mathbf{t}$ & $\mathbf{p}$ \\
\hline Bucal & & & & \\
\hline Min. - Max. & $282.4-410.30$ & $132.3-135.30$ & \multirow{3}{*}{$58.154^{*}$} & \multirow{3}{*}{$<0.001^{*}$} \\
\hline Mean \pm SD. & $387.50 \pm 21.0$ & $133.72 \pm 0.87$ & & \\
\hline Median & 381.30 & 133.90 & & \\
\hline Lingual & & & & \\
\hline Min. - Max. & $86.59-92.65$ & $31.60-34.90$ & \multirow{3}{*}{$146.430^{*}$} & \multirow{3}{*}{$<0.001^{*}$} \\
\hline Mean \pm SD. & $89.73 \pm 1.65$ & $33.23 \pm 0.99$ & & \\
\hline Median & 89.90 & 33.10 & & \\
\hline
\end{tabular}

$\mathrm{t}$ : Student t-test

*: Statistically significant at $\mathrm{p} \leq 0.05$

Table 2: Comparison between the recorded mean micro strain values at the examined surfaces of the implantfor group Aand B under vertical load

\begin{tabular}{|c|c|c|c|c|}
\hline & $\begin{array}{c}\text { Group I } \\
(n=25)\end{array}$ & $\begin{array}{c}\text { GroupII } \\
(n=25)\end{array}$ & $\mathbf{t}$ & $\mathbf{p}$ \\
\hline Bucal & & & & \\
\hline Min. - Max. & $428.40-439.2$ & $228.95-332.2$ & \multirow{3}{*}{$48.501^{*}$} & \multirow{3}{*}{$<0.001^{*}$} \\
\hline Mean \pm SD. & $432.63 \pm 2.76$ & $236.19 \pm 20.06$ & & \\
\hline Median & 432.20 & 232.78 & & \\
\hline \multicolumn{5}{|l|}{ Lingual } \\
\hline Min. - Max. & $129.50-135.8$ & $90.0-92.90$ & \multirow{3}{*}{$110.407^{*}$} & \multirow{3}{*}{$<0.001^{*}$} \\
\hline Mean \pm SD. & $132.73 \pm 1.68$ & $91.37 \pm 0.82$ & & \\
\hline Median & 132.63 & 91.30 & & \\
\hline
\end{tabular}

t: Student t-test

*: Statistically significant at $\mathrm{p} \leq 0.05$

Table 3:Comparison between the recorded mean micro strain values at the examined surfaces of the abutment toothfor group Aand B under oblique load.

\begin{tabular}{|c|c|c|c|c|}
\hline & $\begin{array}{c}\text { Group I } \\
(n=25)\end{array}$ & $\begin{array}{c}\text { GroupII } \\
(\mathrm{n}=25)\end{array}$ & $\mathbf{t}$ & $\mathbf{p}$ \\
\hline Bucal & & & & \\
\hline Min. - Max. & $280.30-282.81$ & $210.0-212.90$ & \multirow{3}{*}{$312.167^{*}$} & \multirow{3}{*}{$<0.001^{*}$} \\
\hline Mean \pm SD. & $281.63 \pm 0.75$ & $211.53 \pm 0.84$ & & \\
\hline Median & 281.69 & 211.60 & & \\
\hline \multicolumn{5}{|l|}{ Lingual } \\
\hline Min. - Max. & $115.0-118.90$ & $96.0-98.80$ & \multirow{3}{*}{$68.521^{*}$} & \multirow{3}{*}{$<0.001^{*}$} \\
\hline Mean \pm SD. & $116.77 \pm 1.14$ & $97.30 \pm 0.85$ & & \\
\hline Median & 116.70 & 97.20 & & \\
\hline
\end{tabular}

t: Student t-test

*: Statistically significant at $\mathrm{p} \leq 0.05$
Table 4: Comparison between the recorded mean micro strain values at the examined surfaces of the implantfor group Aand B under oblique load.

\begin{tabular}{|c|c|c|c|c|}
\hline & $\begin{array}{c}\text { Group I } \\
(n=25)\end{array}$ & $\begin{array}{c}\text { GroupII } \\
(n=25)\end{array}$ & $\mathbf{t}$ & $\mathbf{p}$ \\
\hline Bucal & & & & \\
\hline Min. - Max. & $310.62-313.90$ & $290.70-293.90$ & \multirow{3}{*}{$75.401^{*}$} & \multirow{3}{*}{$<0.001^{*}$} \\
\hline Mean \pm SD. & $312.39 \pm 0.95$ & $292.36 \pm 0.92$ & & \\
\hline Median & 312.40 & 292.15 & & \\
\hline \multicolumn{5}{|l|}{ Lingual } \\
\hline Min. - Max. & $879.0-882.60$ & $639.30-642.64$ & \multirow{3}{*}{$909.95^{*}$} & \multirow{3}{*}{$<0.001^{*}$} \\
\hline Mean \pm SD. & $881.09 \pm 0.94$ & $640.75 \pm 0.92$ & & \\
\hline Median & 88090 & 640.76 & & \\
\hline
\end{tabular}

$*$ : Statistically significant at $\mathrm{p} \leq 0.05$

\section{Discussion}

In vitro studies have been used even more widely than in vivo studies in stress analysis of oral structures, due to the fact that an in vivo test cannot be repeated under the same conditions with the same supporting teeth and mucosa, because the histological structures of the periodontal tissues and bone consistency vary from one patient to another. In addition, the length and width of the roots are different. Thus, comparative studies should be more accurate and practical, if they are performed in a laboratory $[18,19]$. However, the mechanical behavior of the Thermoplasticmaterial used to simulate the PDL in vitro is different from what is expected for the PDL in vivo. This difference should be considered in the interpretation of the results of this study [20].

The incidence of bone resorption is greater in mandible than in the maxilla so mandibular case was used in this study to reduce the risk of bone resorption[21].Because bone is not a homogenous material, predictions of stress magnitude and stress transmission in the human mandible based on the results of this study must be done with caution [22]

In this study, the dental implant was placed posteriorly in the first molar region as this position has been suggested for stabilization and carrying the retentive elements for removable partial over denture and allow the use of a suitable implant length with a safety margin of at least $2 \mathrm{~mm}$ above the mandibular canal $[6,23]$. Also ,it follow and agree with Freitas et al. who stated that implant placement on the molar region can provide better biomechanical configuration, changing Kennedy class I or II to class III [24].

A drilling guide template has been used to facilitate the implant positioning in the accurate position. A clear drilling stent fabricated on a model with the ideal set-up ensures implant placement within the confines of the final denture base[25].

The drilling for the implant site was done by using the manufacture drills starting with the pilot drill, to make sure of the implant sit parallism. Final drilling was done with the final drill to get full contact between the threads of the implant and the surrounding material of the model which will have the great effect on the load transfer from the implant to the supporting structures [26]. 


\section{International Journal of Science and Research (IJSR) \\ ISSN (Online): 2319-7064}

Index Copernicus Value (2013): 6.14 | Impact Factor (2015): 6.391

The choice of telescopic overdenture was based on its greater stability and retention and better distribution of stresses. The greater the vertical space occupied by the tooth preparation, the greater the stabilization provided. Retention is gained by parallel vertical walls of copings [10].A retrospective study was done to evaluate telescopic overdenture abutments found that $96.2 \%$ of abutment teeth were still in situ[27].

Teeth supported overdenture would be the most appropriate treatment option for mandibular partial edentulism. The main advantage of the telescopic overdenture in the present case is providing balanced stress distribution between teeth soft tissues. The telescopic retainers decrease the proportion of most traumatic lateral forces and transmit the occlusal forces in the direction of the long axis of the abutment teeth [28].Furthermore, due to the well stress distribution and continued proprioceptive sensation, telescopic overdenture also prevents residual alveolar bone resorption[29]. It is also more aesthetic and hygienic then conventional removable partial dentures.

Current research data indicate that most dental CAD/CAM systems are now able to produce restorations with acceptable marginal adaptation[30-32].

Despite there are many techniques for stress analysis and evaluation, the strain gauge analysis was used in this study to evaluate strain around abutment teeth as it provides quantitative analysis of the strain around abutment teeth supporting a distal extension partial overdenture (POD) [3335]. This technique is one of the common methods used for dental strain analysis and can overcome many shortcomings of other methods [36].Stafford and Glantz [37].advocated using strain gauges for measuring strains and deformation due to their small size, linearity, and minimal interference during testing.

In this study, trough was made at the sites of the strain gauges for gaining deeper insight into the stress distribution at the implante bone interface [38].

The instillation of strain gauges was done in prepared flat surfaces in the acrylicresin parallel to the long axis of the abutment tooth and the implant and perpendicular to the crest of the ridgefrom four direction (buccal, lingual, mesial and distal) instead of placing the it directly on the root surface or implant surface because it is preferred to bond the strain gauge on completely flat surface tominimize the possibility of obtaining incremental apparent strain that result from mounting the strain gauge on curved surface $[39,40]$.

A load of about $300 \mathrm{~N}$ [16,17] [ $\mathrm{N} \Rightarrow$ Newton] (66 pounds) were applied using the universal testing machine .

For the accuracy of the results, an interval of at least5min between each reading was given to give a chance for heat dissipation from the strain gauge sensors [41].

The materials used in this study was the heat cure thermoelastic acrylic resin. The thermo-elastic acrylic resin is composed of methylmethacrylate which applied in the form of a polymer powder, and a liquid monomer. The monomer is applied in two forms, the softener monomer which is responsible for the flexibility of the finished denture base, and the hardener monomer which is responsible for it rigidity. The degree of the flexibility of the finished denture base depends upon the ratio of the softener monomer to the hardener monomer[42].

Some authors recommended the use of shock-absorbing element in the implant-tooth connected design to prevent the disuse atrophy or other damage to the natural tooth [43-45].

Lin and his co-workers concluded that the use of non-rigid connection might be more efficient in terms of compensation for the dissimilar mobility between the natural teeth and implant under axial loading forces. However, it should be used with caution as it breaks the stress transfer and increases the unfavorable stress values in prosthesis [46].

The increased strains around abutment teeth with RPD retained by telescopic crowns (TRPD) (group A)comparedwith (group B) are in agreement with the results of el Charkawi et al [47] who compared strains between a rigid and a resilient implant system connected to a natural abutment with distal extension RPDs using the technology of strain gauges. The authors found that resilient implant attachments reduced strains around the implant site and allowed redistribution of load between the implant and the abutment teeth by allowing the abutment tooth to share some of the strains with the implant.

For two groups, the buccal surface of abutment teethduring vertical loadingwas associated with the greatest strain. This could be attributed to the shift of the denture in the buccal direction during force application on the loading side, ashad a lower resistance to lateral movement compared, The lateral movements cause a compressive strain to the upper edges of the buccal cortical bone plate, which had the potential tendency to be displaced outward in the horizontal plane. The presence of the rigid implant hindered these displacements and led to increased strain on the buccal side of abutments [48].

Vertical Loads were applied at the premolars/ molars region [49] of the overdenture. Such a loading location was selected as it seemed to be the center of the overdenture around which chewing center will be located as suggested by Zarb.

Reduction of stress to the distal-extension base was observed with the resilient layer (groups B), compared with the nonresilient group (control, group A). Thus the results of the present study elucidate that the retention values of Thermoelastic acrylic resin TOD was greater than hard acrylic resin TOD.This is in accordance with Tokueet al. [50]that illustrate an important advantage of the thermo-elastic resins that it has an internal memory to return to its original position.

\section{Conclusion}

This study was performed to evaluate theeffect of unilateral mandibular implant -tooth supported telescopic prosthesis on the supporting structures. Ten lower kennedy class II partially edentulous model were constructed to receive implant at firstmolar area, then divided into 2 groups either(Group A: (unilateral implant -tooth supportedtelescopic over denture with hard acrylic 


\section{International Journal of Science and Research (IJSR) \\ ISSN (Online): 2319-7064}

Index Copernicus Value (2013): 6.14 | Impact Factor (2015): 6.391

base)(UTOD)Group B: (unilateral implant -tooth supported telescopic over denture (UTOD) lined with thermo elastic material) .each groups receive removable partial denture of the same design. The results showed statically difference between the treatment plans. It could be concluded that unilateral implant -tooth supported telescopic over denture (UTOD) lined with thermo elastic material may be simple solution for Kennedy class II partial denture.considered as more favorable solution and better stress distribution.

\section{References}

[1] I.A. Dahab, A.A. El-Gendy, I.R.Eltorky,"In vitro stress analysis study of different prosthetic options using single posterior implant for management of mandibular unilateral distal extension saddle," Tanta Dent J, 12,p. 7-15, 2015.

[2] A.B. Carr, D.T. Brown,"McCraken's removable partial prosthodontics," 12th ed, St Louis, Mosby Co, 103e15, 6, 21, 2011.

[3] A.B. Can, G.P. McGiveny, D.T. Brawn,"McCracken's removable partial prosthodontics," 11th ed, Mosby, Imc, pp. 160-169, 2005.

[4] P.A. Abraham, P. Koka, K. Murugesan, M. Vasanthakumar,"Telescopic overdenture supported by a combination of tooth and an implant: a clinical report," J Indian ProsthodontSoc, 10, 230, 2010.

[5] M. Kihara, Y. Matsushita, M. Tokuhisa,"The effect of implant support for extended removable partial dentures -experimental studies in a model missing mandibular posterior teeth," J Nippon KokuInpurantoGakkaishi, 16, pp. 214-225, 2003.

[6] H.M. Keltjens, A.F. Kayser, R. Hertel, P.G. Battistuzzi,"Distal extension removable partial dentures supported by implants and residual teeth: considerations and case reports,"Int J Oral Maxillofac Implants, 8, pp. 208-313, 1993.

[7] F.R. Verri, E.P. Pellizzer, E.P. Rocha, J.A. Pereira,"Influence of length and diameter of implants associated with distal extension removable partial dentures," Implant Dent, 16, pp. 270-280, 2007.

[8] F.M. Chieh, S.Y. Wen, F.L. Jyh,"Clinical application of implant-supported bilateral distal extension removable partial denture-case report," J Dent Sci, 2, 52-56, 2007.

[9] T. Widbom, L. Lofquist, C. Widbom, B. Soderfeldt, M. Kronstrom,"Tooth-supported telescopic crown-retained dentures: an up to 9-year retrospective clinical follow-up study,"Int J Prosthodont, 17, pp. 29-34, 2004.

[10] W.P. Harold, A. Kristina, H. Alfred, M. Regina,"Overdentures Made Easy. A Guide to Implant and Root Supported Prostheses, London, Quintessence Publishing Co Ltd, pp. 45-66, 1996.

[11] H.J. Nickenig, H. Spiekermann, M. Wichmann, S.K. Andreas, S. Eitner,"Survival and complication rates of combined tooth-implant-supported fixed and removable partial dentures, "Int J Prosthodont, 21, pp. 131-137, 2008.

[12] G. Amandeep, N.K. Aggarwal1,"Telescopic overdentures with cercon primary coping and gold galvano secondary coping, J Dent Implants, 2012.

[13] S. Witkowski, F. Komine, T. Gerds,"Marginal accuracy of titanium copings fabricated by casting and
CAD/CAM techniques," J Prosthet Dent, 96, pp. 47-52, 2006.

[14] D. Y. I. Zaki, A. R. A. Moussa, A. W. AbouZeid,"Dynamic Mechanical Thermal Analysis of a Multipurpose Thermo-Elastic Acrylic Resin With Different Softener/Hardener Monomer Ratios,"Aust J Basic ApplSci,6, pp. 695-699, 2012.

[15] M. Karl, A. Dickinson, S. Holst, A. Holst,"Biomechanical methods applied in dentistry: a comparative overview of photoelastic examinations, strain gauge measurements, finite element analysisand three-dimensional deformation analysis,"Eur J ProsthodontRestor Dent, 17, pp. 50-57, 2009.

[16] W. D. Thompson, F. J. Kratochvil, A. A. Caputo, "Evaluation of photoelastic stress patterns produced by various designs of bilateral distal-extension removable partial dentures," J Prosthet Dent, 91, pp. 105-113, 2004.

[17] C. P. Fernandes, P. O. Glantz, S. A. Svensson, A. Bergmark, "A novel sensor for bite force determinations," Dent Mater, 19, pp. 118-126, 2003.

[18] A. Asundi, A. Kishen,"A strain gauge and photoelastic analysis of in vivo strain and in vitro stress distribution in human dental supporting structures," Arch Oral Biol, 45, pp. 543-550, 2000.

[19] T. Jemt,"Implant treatment in elderly patients,"Int J Prosthodontics, 6, pp. 456-461, 1993.

[20] M. K. Maria, M. A. Awadallah. M. A. Gad,"Construction of soft tissue replica on stone model," ADJ, 16, pp. 41-52, 1991.

[21] H. Shohet,"Relative magnitudes of stress on abutment teeth with different retainers," J Prosthet Dent, 21, pp. 267-282, 1969.

[22] K. Craig, "Restorative dental material," 11th ed. St. Louis, MO, Mosby, pp. 77-88, 1994.

[23] C. E. Misch, E.A. Crawford,"Predictable mandibular nerve location a clinical zone of safety,"Int J Oral Implant, 7, p. 37, 1990.

[24] R. F. De Freitas, K. de Carvalho Dias, A. da Fonte Porto Carreiro, G. A. Barbosa, M. A. Ferreira,"Mandibular implant-supported removable partial denture with distal extension: a systematic review," J Oral Rehabil, 39, pp. 791-798, 2012.

[25] R.C. Vogel,"Implant overdentures: a new standard care edentulous patients current concepts techniques,"CompendContinEduc Dent, 29, pp. 270276, 2008.

[26] A. Rahimi, C. Bourauel, A. Jager, T. Gedrange, F. Heinemann,"Load transfer by fine threading the implant neckea FEM study," J PhysiolPharmacol, 60(Suppl. 8), pp. 107e-112, 2009.

[27] P. Rehmann, A. Weber, B. Wöstmann, P. Ferger,"Clinical evaluation of teeth fitted with telescope crowns for retaining a partial denture," DZZ, 62, pp. 99-103, 2007.

[28] K. Singh, N. Gupta, "Telescopic denture - a treatment modality for minimizing the conventional removable complete denture problems: a case report,'J ClinDiagn Res, 6, pp. 1112-1116, 2012.

[29] A. V. Pramod Kumar, T. K. Vinni, and M. R. Mahesh, "Full mouth rehabilitation with maxillary tooth supported and mandibular tooth and implant supported combination prostheses: a 4-year case report,"J Indian ProsthodontSoc, 12, pp. 113-119, 2012. 


\section{International Journal of Science and Research (IJSR) \\ ISSN (Online): 2319-7064}

Index Copernicus Value (2013): 6.14 | Impact Factor (2015): 6.391

[30] L. A. Ellingsen, D. J. Fasbinder,"In vitro evaluation of CAD/CAM ceramic crowns," J Dent Res, 81, p. 331, 2002.

[31] J. Tinschert, G. Natt, W. Mautsch, H. Spiekermann, K. J. Anusavice,"Marginal fit of alumina- and zirconiabased fixed partial dentures produced by a CAD/CAM system,"Oper Dent, 26, pp. 367-374, 2001.

[32] G. Hertlein, M. Kraemer, T. Sprengart, K. Watzek,"Milling time vs. marginal fit of CAD/CAMmanufactured zirconia restorations," J Dent Res, 82, p. 194, 2003.

[33] H. G. el Charkawi, K. A. Zekry, M. T. el Wakad,"Stress analysis of different osseointegrated implants supporting a distal extension prosthesis," J Prosthet Dent, 72, pp. 614-622, 1994.

[34] T.S.P. Lacerda, D.C. Lagana, R. G. Lima RG, A. L. Zanetti, "Contribution to the planning of implantsupported RPD in the distal region," RPG Rev Pos Grad, 12, pp. 293-300, 2005.

[35] R. C. Rodrigues, A. C. Faria, A. P. Macedo, G. de MattosMda, R. F. Ribeiro,"Retention and stress distribution in distal extension removable partial dentures with and without implant association," J Prosthodont Res, 57, pp. 24-29, 2013.

[36] M. C. Cehreli, H. Iplikcioglu,"In vitro strain gauge analysis of axial and off-axial loading on implant supported fixed partial dentures," Implant Dent, 11, pp. 286-292, 2002.

[37] G. D. Stafford, P. O. Glantz,"Intraoral strain gauge measurements on complete dentures: a methodological study," J Dent, 19, pp. 80-84, 1991.

[38] M. Karl, M. G. Wichmann, W. Winter, F. Graef, T. D. Taylor, S. M. Heckmann,"Influence of fixation mode and superstructure span upon strain development of implant fixed partial dentures," J Prosthodont, 17: p. 38, 2008.

[39] A. A. El-Gendy,"Micro-strain evaluation of different implant positions supporting mandibular bilateral distal extension partia over denture," Tanta Dental J, 4, pp. 39-46, 2007.

[40] K, Akca, M. C. Cehreli, H. Iplikcioglu,"A comparison of threedimensional finite element stress analysis with in vitro strain gauge measurements on dental implants,"Int J Prosthodont, 15, pp. 115-121, 2002.

[41] C. Cekic, K. Akca, M. C. Cehreli,"Effects of attachment design on strains around implants supporting overdentures," Quintessence Int, 38, pp. 291-297, 2007.

[42] M. M. El Zwahry,"Stress analysis and evaluation of a flexible denture base material. PhD Thesis, Prosthodontics Department, Faculty of Dentistry, Azhar University, 2006.

[43] M. S. Block, D. Lirette, D. Gardiner, L. Li, I. M. Finger, J. Hochstedler, et al,"Prospective evaluation of implants connected to teeth," Int J Oral Maxillofac Implants, 17, pp. 473-487, 2002.

[44] T. Jemt,"Modified single and short-span restorations supported by osseointegrated fixtures in the partially edentulous jaw," J Prosthet Dent, 55, pp. 243-247, 1986.

[45] T. J. Balshi,"Osseointegration for the periodontally compromised patient,"Int J Prosthodont, 1, pp. 51-58, 1988.
[46] C. Hita-Carrillo, M. Hernandez-Aliaga, J. L. CalvoGuirado,"Tooth-implant connection: a bibliographic review," Med Oral Patol Oral Cir Bucal, 15, 387-394, 2010.

[47] H. G. el Charkawi, K. A. Zekry, M. T. el Wakad,"Stress analysis ofdifferent osseointegrated implants supporting a distal extensionprosthesis," J Prosthet Dent, 72, pp. 614-622, 1994.

[48] E. Kitamura, R. Stegaroiu, S. Nomura, O. Miyakawa,"Biomechanical aspects of marginal bone resorption around osseointegrated implants: considerations based on a three-dimensional finite element analysis,"Clin Oral Implants Res, 15, pp. 401412, 2004.

[49] C. H. Zhang, H. Wei, Y. Liu, H. Tan, Z. Guo, "Enhanced toughness and shape memory behaviors of toughed epoxy resin," High Perform Polym, 24,pp. 702-709, 2012.

[50] A. Tokue, T. Hayakawa, C. Ohkubo,"Fatigue resistance and retentive force of cast clasps treated by shot peening," J Prosthodont Res, 57, pp. 186-194, 2013.

\section{Author Profile}

Isaeida Abdulla Ali Mohamed received the B.D.S. in Dental and Oral Surgery from Benghazi University, Faculty of Dentistry 2008. During 2008-2009, she practiced in Ministry of Health. Since 2009-2012, she worked as a demonstrator in Benghazi University. During 2012 till now, she educated for M.S degree in prosthodontics in prosthetic department, Faculty of dentistry. Alexandria University. 